\title{
Integração entre projeto e obra em empreendimento público rodoviário
}

\author{
Design-build integration in public highway project
}

\section{Ronan Lana Alves Moreira \\ Paulo Roberto Pereira Andery}

\section{Resumo}

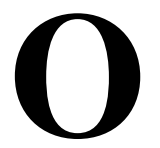

presente trabalho tem como objetivo identificar as alterações no desenvolvimento de projetos de obras públicas que utilizam a modalidade de Contratação Integrada do Regime Diferenciado de Contratação. A pesquisa desenvolveu-se no marco metodológico de estudo de caso, compreendendo tanto a análise do processo de projeto de duplicação de rodovia a partir de entrevistas semiestruturadas com especialistas na área quanto a análise de documentos do empreendimento.O estudo identificou possíveis melhorias nos mecanismos de integração entre as fases de projeto e obra, analisando de que forma a Contratação Integrada contribui para a adoção das melhores práticas do modelo Design-build. Os resultados apontam para o fato de que, independentemente de questões legais, a Contratação Integrada abre oportunidade para a aplicação dos conceitos e processos de desenvolvimento integrado de projetos. Contudo, a melhoria da construtibilidade e integração entre projeto e obra exige melhorias nas especificações contratuais, além da formalização de fluxos específicos para o processo de projeto. $\mathrm{O}$ artigo é relevante na medida em que contribui com o estudo de formas de contratações alternativas à Lei no 8.666/1993, como é o caso da Contratação Integrada, tema ainda recente no âmbito de pesquisas desenvolvidas no Brasil.

Palavras-chave: Gestão do processo de projeto. Regime Diferenciado de Contratação. Contratação Integrada. Integração projeto-obra.

\section{Abstract}

The aim of thisproject is to identify changesin the delivery of public projects under the Brazilian Integrated Contracting bidding system. The research was carried out using the case study method, focusing on the analysis of the process of a highway duplication project. Semi-structured interviews with field specialists were conducted, as well as an analysis of the project documents. The studyidentifies possible improvements in design and construction integration, analysing to what extent Integrated Contracting contributes to the adoption of the best practices of

${ }^{1}$ Ronan Lana Alves Moreira ${ }^{1}$ Universidade Federal de Minas Gerais Belo Horizonte - MG - Brasil

${ }^{2}$ Paulo Roberto Pereira Andery

${ }^{2}$ Universidade Federal de Minas Gerais Belo Horizonte - MG - Brasil

Recebido em 05/12/19 Aceito em 11/03/20 the design-build model. The results point to the fact that, regardless of anylegal issues, Integrated Contracting opens an opportunity for the application of Integrated Project Deliveryconcepts and processes. However, constructibility improvements require not onlybetter contractual specifications, but also the implementation of design processes workflows. This study contributes to the study of alternative bidding mechanisms to Brazilian Law 8.666/93, as is the case of Integrated Contracting, which is still a scarcelyresearchedsubject in Brazil.

Keywords: Design management process. Integrated contracting. Design-construction integration. 


\section{Introdução}

A indústria da construção civil enfrenta constantes desafios na condução de projetos devido à incompatibilidade de alocação de riscos, à inexperiência dos contratados, à falta de qualificação de corpo técnico e à fragmentação de contratos (MCKINSEY..., 2017; SERRADO et al., 2019). Uma das causas dessa falta de integração está relacionada ao modelo de contratação padrão da indústria que separa as atividades de projetos e obras, particularmente na contratação de obras públicas (SULLIVAN et al., 2017).

$\mathrm{Na}$ tentativa de melhorar essa integração, condição essencial para o aumento da construtibilidade, a Federal Highway Administration (FWHA), nos Estados Unidos, autorizou no ano de 1990 o uso experimental de métodos inovadores de contratação de empreendimentos. Entre os métodos, o que tem sido mais utilizado é o Design-build, que contempla a execução conjunta do projeto e da obra por um único agente, quer seja empresa ou consórcio (MINCHIN JUNIOR et al., 2013).

Esse método pode ser considerado de maneira mais ou menos ampla: por um lado, pode ser entendido como uma estrutura de contratação na qual o desenvolvimento dos projetos (design) e sua execução são realizados por um único agente, havendo, portanto, uma única fonte de responsabilidade (CHO et al., 2010). Por outro lado, assumindo esse mecanismo de contratação, pode ser desenvolvido todo um sistema de produção, integrando as etapas de projeto e execução, o que potencializa o uso de conceitos inovadores na gestão do processo de projeto (PARK; KWAK, 2017).

Em comparação com os métodos tradicionais de contratação, diversaspesquisas apontam que o Design-build tende a reduziros prazos de execução dos empreendimentos, sendo promissor em termos de redução de custos (SULLIVAN et al., 2017; PARK; KWAK, 2017; TRAN; DIRAVIAM; MINCHIN JUNIOR, 2018), ainda que essas vantagens dependam do tipo de empreendimento desenvolvido (TRAN; DIRAVIAM; MINCHIN JUNIOR, 2018).

No caso brasileiro, o Governo Federal instituiu em 2011 a Contratação Integrada, a qual permite que uma única organização seja responsável pela elaboração do projeto, pelas soluções e pela execução das obras a partir de parâmetros definidos em um anteprojeto de engenharia (NÓBREGA, 2015). Foi uma inovação com relação à Lei Geral das Licitações (BRASIL, 1993), que determina que as contratações sejam precedidas de, no mínimo, um projeto básico.

A Contratação Integrada é permitida nos empreendimentos que apresentem comprovadamente características de inovação, com o repasse de tecnologias para o contratante. A responsabilidade técnica pelo desenvolvimento dos projetos de engenharia é concentrada na empresa ou no consórcio responsável pela execução do empreendimento. Dessa maneira, cabe ao contratante definir um anteprojeto de engenharia e verificar a adequação dos projetos desenvolvidos à proposta inicial, não sendo permitida a celebração de aditivos (BRASIL, 2011).

Após alguns anos de utilização do novo modelo, o Tribunal de Contas da União (TRIBUNAL..., 2017) sugeriu que as licitações sob o novo regime tiveram piores resultados quando comparadas às licitações tradicionais, em termos de descontos obtidos e eficácia das licitações. Como são ainda poucas e recentes as obras, não há estudos significativos a respeito do desempenho quanto a prazos e custos, o que gera uma oportunidade para pesquisas.

Em outra análise, o Sindicato da Arquitetura e da Engenharia (Sinaenco) (SINDICATO..., 2019) chegou à conclusão de que, dos 35 contratos regidos pela Contratação Integrada que estavam encerrados no momento do estudo, $60 \%$ tiveram aditivos de prazo e 57,1\% tiveram aditamento de valor. O documento ainda aborda a visão do Sindicato a respeito do anteprojeto de engenharia, considerando-o ineficaz para controle de qualidade, prazo e custo do empreendimento.

O TCU (TRIBUNAL..., 2017), inclusive, constatou que 79\% dos empreendimentos fiscalizados regidos pela Contratação Integrada apresentaram indícios de irregularidades no anteprojeto e acrescentou que os gestores públicos não estão definindo de maneira detalhada o nível de qualidade esperado dos empreendimentos.

Contudo, essa modalidade contratual poderia, em função da forma de contratação, aproximar-se dos conceitos de Design-build, com a possível melhora na integração entre projetos e obras, o que exigiria alterações no processo de desenvolvimento das disciplinas de projeto (FREIRE; BOMTEMPO; ANDERY, 2016). Aqui o Design-build é considerado como um sistema de entrega de projetos, sem considerar somente os aspectos legais de contratação. Em outras palavras, trata-se de um sistema de gestão das etapas de concepção, projeto e execução que, assumindo diretrizes específicas, pode favorecer a utilização de 
princípios de desenvolvimento simultâneo e integrado das disciplinas de engenharia, visando ao aumento da construtibilidade (PARK; KWAK, 2017).

Nesse sentido, o presente trabalho contribui com o estudo da gestão do processo de projeto em obras públicas, investigando em que medida os processos da Contratação Integrada permitem a adoção de melhores práticas de projeto, em particular em relação à integração com a fase de obras, à semelhança das melhores práticas do Design-build.

Como ainda são escassos os estudos com essa abordagem, o trabalho contribui especificamente com um diagnóstico sobre eventuais mudanças no processo de projeto e potenciais melhorias advindas da implementação da Contratação Integrada. Por outro lado, o trabalho não analisa aspectos como especificidades do marco legal, que tem sido objeto mais frequente de estudos na área.

\section{Referencial teórico}

O referencial teórico abordou os principais estudos, comparativos e conceitos sobre o método de aquisição Design-build, bem como as melhores práticas na gestão de projetos integrados, como é o caso da Engenharia Simultânea e Integrated Project Delivery.

\section{Design-build}

O Design-build é um dos métodos alternativos de desenvolvimento de projetos mais utilizados em empreendimentos públicos nos Estados Unidos, especialmente em infraestrutura de transportes (GATTI; MIGLIACCIO; LAIRD, 2014).

Segundo Cho et al. (2010), a característica primordial do Design-build é ter uma única fonte de responsabilidade pelo projeto e pela condução das obras, podendo o modelo assumir várias abordagens, dependendo dos critérios de contratação.

O Design-build abre oportunidade para o envolvimento do construtor desde as etapas iniciais do ciclo de vida do projeto (SULLIVAN et al., 2017), facilitando adaptações e soluções de problemas durante a execução do empreendimento (PARK; KWAK, 2017). Contudo, Tran, Diraviam e Minchin Junior (2014) salientam que o pouco detalhamento do projeto preliminar na fase de contratação pode acarretar mais riscos e incertezas do que nos contratos convencionais.

Com baseem diversos autores, Yu, Shen e Shi (2017) elaboraram um estudo das principais características contratuais do Design-build (DB) em comparação com o método padrão da indústria da construção, conhecido como Design-bid-build (DBB), conforme sinteticamente apresentado no Quadro 1.

Além das características contratuais, é possível também identificar a diferença entre o DB e o DBB no que tange ao macrofluxo do processo de contratação e condução do empreendimento, conforme demonstrado por Park e Kwak (2017) no diagrama da Figura 1.

\section{Quadro 1 - Comparação entre os métodos de entrega DB e o DBB}

\begin{tabular}{|l|c|c|}
\hline \multicolumn{1}{|c|}{ Critério de análise } & DB & DBB \\
\hline Modo de pagamento & $\begin{array}{c}\text { Única fonte de } \\
\text { pagamento }\end{array}$ & $\begin{array}{c}\text { Projetista e } \\
\text { empreiteiro em } \\
\text { separado }\end{array}$ \\
\hline Grau de colaboração entre o projetista e o empreiteiro & Alto & Baixo \\
\hline Riscos para o contratante & Baixos & Altos \\
\hline Riscos para o projetista e para o empreiteiro & Altos & Baixos \\
\hline Responsabilidade e envolvimento do contratante & Baixa & Alta \\
\hline Responsabilidade e envolvimento do projetista e empreiteiro & Alta & Baixa \\
\hline Custos do projeto e construção para os contratados & Incertos & Incertos \\
\hline Custos de coordenação/comunicação para os contratados & Altos & Baixos \\
\hline Custos de gestão para o contratante & Baixos & Altos \\
\hline
\end{tabular}

Fonte: traduzido e adaptado de Yu, Shen e Shi (2017). 
Figura 1 - Comparação do desempenho do cronograma entre DB e DBB
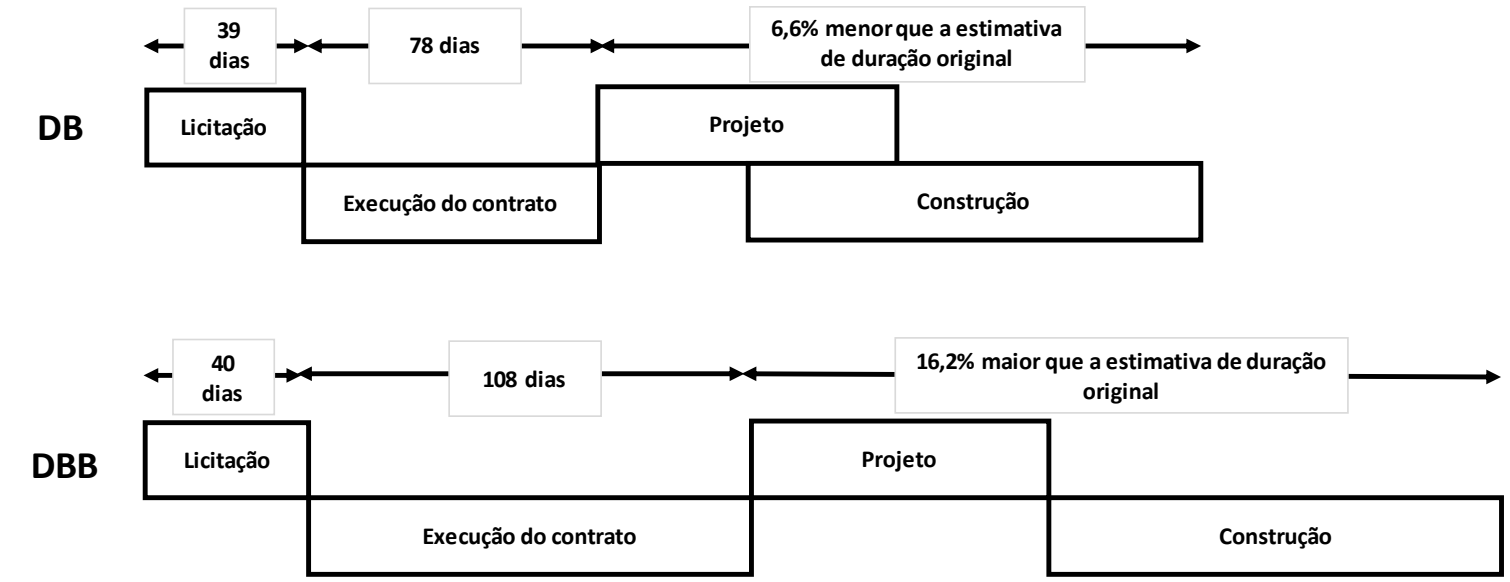

Fonte: Park e Kwak (2017).

Conforme se verifica no macrofluxo, Park e Kwak (2017) concluíram, a partir de estudo empírico, que o DB possibilitou a redução de 6,6\% na estimativa de duração original do empreendimento, enquanto o modelo DBB apresentou 16,2\% de acréscimo na duração prevista do empreendimento.

Em pesquisa mais abrangente, Sullivan et al. (2017) fizeram uma compilação de estudos de duas décadas sobre métodos alternativos de entrega de projetos em comparação com o método tradicional. Os autores concluíram que entre os dois sistemas de contratação não houve diferenças estatisticamente relevantes em relação acustos. Porém, no que diz respeito a prazos, o DBse mostrou melhor, com aditivo médio na ordem de $10,7 \%$, em detrimento da média de 18,4\% encontrada no DBB. Os autores concluíram que o DBtanto pode aumentar a velocidade de entrega de um projeto, quanto aumentar a certeza de sua duração.

No quesito de atendimento aos requisitos especificados de qualidade, o estudo de Sullivan et al. (2017) não conseguiu chegar à conclusão sobre possíveis vantagens do método alternativo de contratação em relação ao método tradicional.

Park e Kwak (2017) salientam que o DBnão pode ser utilizado de maneira indiscriminada, tendo em vista os riscosenvolvidosna contratação, o que pode resultar em propostas que oferecem incertezas quanto ao atendimento aos objetivos do empreendimento. Dessa maneira, o DBé o método mais apropriado para grandes projetos, em que os contratantes procuram maior certeza de custos e aceleração de prazos, com aumento da flexibilidade.

No âmbito brasileiro, são ainda poucos os projetos públicos que utilizaram o regime Contração Integrada que foram objeto de estudo. Freire, Anderye Bomtempo (2016) constataram que a Contratação Integrada fornece uma estrutura contratual que possibilita maior integração entre os agentes. No entanto, verificaram que, no caso que estudaram, as práticas de projeto pouco se distinguiram das tradicionais, ainda que tenham sido observados alguns avanços na introdução de medidas de melhoria da construtibilidade.

Mais recentemente, Zacharias et al. (2019) estudaram o Regime Diferenciado de Contratação em obras públicas de infraestrutura, tendo apontado para o mesmo resultado acima. Por outro lado, ressaltaram que esse regime de contratação possibilita maior atuação da coordenação de projetos, permitindo a estruturação de um fluxo de projetos que facilite a colaboração entre os agentes, e a integração entre as etapas de projeto e obra.

\section{Melhores práticas em gestão de projetos integrados}

Diversos autores sugerem ações no sentido de potencializar os resultados do DB no que diz respeito à gestão do processo de desenvolvimento de projetos.A partir de estudos de casos práticos, pode-se resumidamente destacar as principais ações para gestão nesse tipo de contratação, indicadas a seguir:

(a) identificar e envolver os principais interessados do projeto nas fases iniciais de planejamento fomentando a participação precoce dos empreiteiros e principais fornecedores (DESIGN..., 2014); 
(b) priorizar requisitos baseados em desempenho em vez de prescrições normativas, permitindo que a contratada assuma as soluções com inovação e criatividade (DESIGN..., 2014);

(c) conduzir formalmente o gerenciamento de riscos, identificando fatores que possam influenciar a condução do empreendimento (TRAN; MOLENAAR, 2014);

(d) formalizar contratualmente a colaboração e a interação das equipes multidisciplinares a partir de fluxos específicos para projetos integrados (LING; POH, 2008; DESIGN..., 2014);

(e) fornecer treinamento e capacitação sobre as vantagens e benefícios da integração entre projeto e obra quando trabalhada de maneira colaborativa (FEDERAL..., 2006; LING; POH, 2008; DESIGN..., 2014);

(f) criar ferramentas para subsidiar a comunicação formal e informal na tomada de decisão, incluindo pleno conhecimento de todas as interações entre projetos e programas envolvidos (GATTI; MIGLIACCIO; LAIRD, 2014); e

(g) criar sistema de incentivo com foco na redução de custos e/ou prazos, podendo, inclusive, utilizar o processo de economia compartilhada entre contratante e contratada (GATTI; MIGLIACCIO; LAIRD, 2014).

Além das práticas expostas, Park e Kwak (2017) constataram que o principal objetivo do DB é acelerar o processo de gestão de projeto por meio de conceitos e métodos que fortaleçam a colaboração e a integração entre as etapas de projeto e execução, como é o caso da Engenharia Simultânea, o que até o momento não vem acontecendo de forma ideal.

A Engenharia Simultânea é uma visão sistemática do desenvolvimento integrado e simultâneo dos produtos e seus processos relacionados, incluindo manufatura e assistência, considerando todo o ciclo de vida do empreendimento (BOUCHLAGHEM et al., 2006).O conceito evoluiu e foi incorporado às práticas de Integrated Project Delivery, que, além dos aspectos mencionados acima, considera a introdução de contratos relacionais, nos quais empreendedor, construtor e os principais projetistas constituem uma aliança, compartilhando responsabilidades, riscos e resultados do empreendimento (AMERICAN..., 2007).

Uma síntese desses conceitos é apresentada por Kunz e Fischer (2020), que afirmam que o desenvolvimento integrado de projetos implica que representantes do empreendedor, projetistas, construtor e responsáveis pela operação constituem uma equipe multidisciplinar, trabalhando de maneira colaborativa para especificar, criar e aplicar um modelo que envolva a definição de uma estrutura organizacional, processos e procedimentos, que vão evoluindo gradativamente ao longo do ciclo de vida do projeto. Esse modelo está orientado à obtenção de métricas específicas para a garantia do desempenho do projeto.

Os processos de desenvolvimento simultâneo e integrado de projetos (design) preconizados pelo Integrated Project Delivery implicam (AMERICAN..., 2007):

(a) valorização da elaboração do programa de necessidades (briefing) dos empreendimentos;

(b) consideração sistemática, desde as primeiras etapas da concepção, dos aspectos de produção, incorporando conceitos de construtibilidade; e

(c) formação de equipes multidisciplinares e adoção de processos estruturados de desenvolvimento de coordenação de projetos, utilizando tecnologias de colaboração, em especial o Building Information Modeling (BIM).

Esses aspectos de integração são potencializados com a utilização de BIM. Eastman et al. (2014) e Bradley et al. (2016) sugerem que a utilização de BIM alcança maiores patamares de colaboração, implicando melhoria de construtibilidade, àmedida que os sistemas de desenvolvimento dos empreendimentos priorizarem a integração entre os agentes responsáveis por projeto e execução das obras.

As dificuldades na adoção de abordagens integradas em empreendimentos de construção parecem ser maiores em empreendimentos públicos, dadas as resistências àadoção de modelos que não se fundamentemem licitações baseadas frequentemente no menor custo (KIM et al., 2016).

\section{Método de pesquisa}

O presente trabalho adotou o método do Estudo de Caso Exploratório tendo em vista a complexidade envolvida em uma temática ainda pouco investigada (GIL, 2008). No intuito de se ter uma visão geral do assunto, a pesquisa foi desenvolvida em análise do processo de projeto de parte de um empreendimento de duplicação de rodovia federal e pesquisa de percepções dosespecialistas conforme as fases a seguir: 
(a) Definição do problema de pesquisa, que foi dividido em questões de pesquisa para nortear a investigação. São estas: em que medida a Contratação Integrada oferece mecanismos que facilitem a integração entre as fases de projeto e obra? Em que medida a Contratação Integrada se assemelha ao DB? A estrutura legal e organizacional dos empreendimentos permite ou induz a adoção de conceitos de desenvolvimento integrado de projetos, assumindo conceitos da Engenharia Simultânea?

(b) Revisão da literatura, que aborda especificamente estudos relevantes sobre comparativos do DB em relação aos métodos tradicionais, bem como as melhores práticas na gestão de projeto integrados.

(c) Definição de empreendimento que pudesse ser objeto de estudo de caso. Foram empregados como critérios para seleção:

- empreendimento ter sido objeto de Contratação Integrada;

- haver processos de desenvolvimento documentados e acessíveis;

- rastreabilidade e confiabilidade das informações; e

- disponibilidade para colaboração na pesquisa.

(d) Estudo de caso desenvolvido em duas etapas (estudo de caso e pesquisa de percepção), conforme detalhado a seguir.

\section{Estudo do processo de projeto}

O estudo de caso foi desenvolvido mediante entrevistas semiestruturadas com coordenadores de projetos e equipe de obras abordando o processo de projeto, sua integração com a obra, atividades simultâneas, equipes multidisciplinares e uso de tecnologia da informação. Além disso, foram analisadas outras fontes de evidências, conforme indicado no Quadro 2.

O estudo de caso foi desenvolvido em um dos principais corredores rodoviários do estado de Minas Gerais. Devido à complexidade e ao volume do empreendimento, o escopo do trabalho restringiu-se ao processo de projeto relativo a um dos lotes que está com contrato em andamento. O lote foi escolhido devido a sua integração com várias obras de arte especiais, além da existência de contratos adjacentes, como o caso de túneis, exemplificado na Figura 2.

Para essa etapa foram realizadas sete entrevistas com engenheiros das áreas de projetos e obras, tanto da parte contratante quanto da parte contratada. Os roteiros de entrevistas foram semiestruturados, contendo questões referentes à descrição do processo de projeto, ao papel da coordenação ea mecanismos de interação entre equipe de obras e equipe de projetos, e foram dirigidos aos engenheiros que trabalharam no empreendimento.

\section{Quadro 2 - Principais fontes de evidências utilizadas}

\begin{tabular}{|l|l|}
\hline \multicolumn{1}{|c|}{ Fonte de Evidência } & \multicolumn{1}{c|}{ Objetivo } \\
\hline $\begin{array}{l}\text { Guias e normativos da } \\
\text { contratante }\end{array}$ & $\begin{array}{l}\text { Verificar aspectos gerais de condução de empreendimentos sob o } \\
\text { regime de Contratação Integrada }\end{array}$ \\
\hline $\begin{array}{l}\text { Edital de licitação e anteprojeto } \\
\text { de engenharia }\end{array}$ & $\begin{array}{l}\text { Verificar aspectos específicos do estudo de caso, tais como grau de } \\
\text { responsabilidades, riscos, remuneração e parâmetros de } \\
\text { desempenho }\end{array}$ \\
\hline $\begin{array}{l}\text { Relatório de termos de aceite de } \\
\text { projeto }\end{array}$ & $\begin{array}{l}\text { Colaborar para a elaboração de um fluxo do processo de projeto } \\
\text { específico para a Contratação Integrada }\end{array}$ \\
\hline Projeto executivo de engenharia & $\begin{array}{l}\text { Fazer comparativo pontual das alterações relatadas em entrevistas } \\
\text { em relação ao anteprojeto de engenharia }\end{array}$ \\
\hline
\end{tabular}


Figura 2 - Ligação entre pontes e túneis no trecho escolhido para a pesquisa (11/03/19)

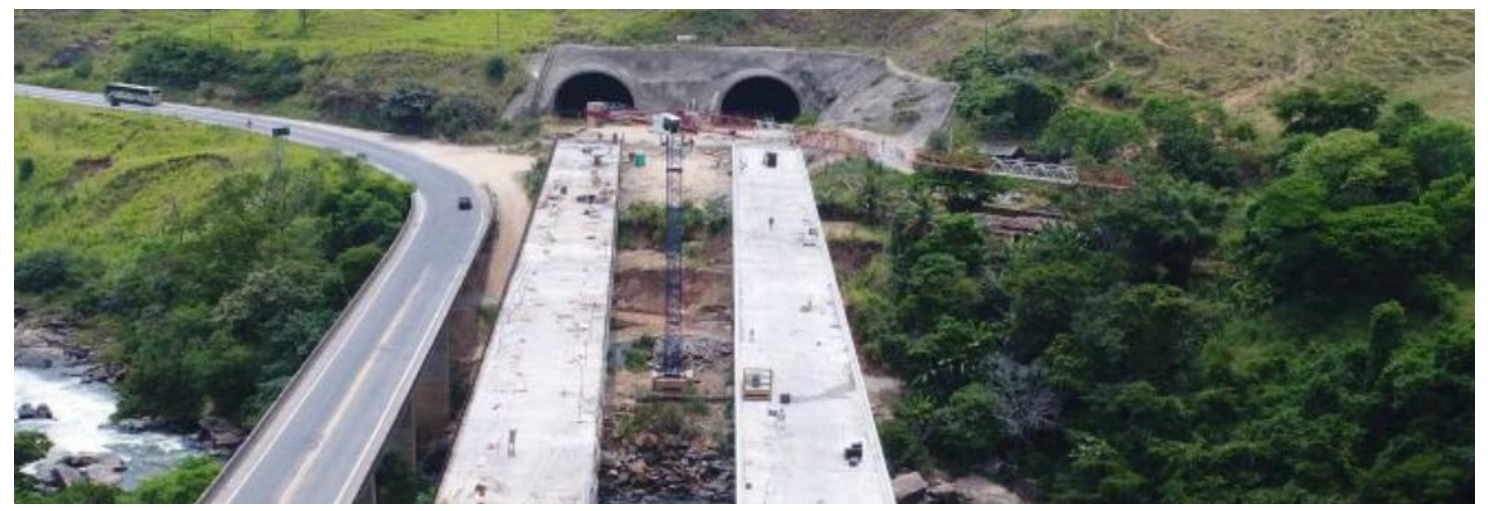

Fonte: DNIT (DEPARTAMENTO..., 2018b).

Os respondentes eram, por parte da contratante,coordenador de engenharia, responsável pelo serviço de projeto, responsável pelo serviço de construção, analista de projeto geométrico, analista de projeto de obras de arte especiais e fiscal de obras. Por parte do contratado foi entrevistado o gestor do contrato responsável pelo projeto e obra.

\section{Pesquisa de percepção dos especialistas}

A segunda etapa contou com a aplicação de questionários semiestruturados dirigidos a especialistas (engenheiros projetistas, engenheiros de obras, fiscais e supervisores), envolvidos ou não no estudo de caso, com o objetivo de apurar a percepção de cada um sobre as vantagens e desvantagens da Contratação Integrada. O questionário contou com perguntas objetivas sobre as questões de custo, prazo e qualidade, bem como sobre a aplicabilidade da Contratação Integrada.

Para essa etapa foram feitas entrevistas com engenheiros que já participaram de empreendimentos regidos pela Contratação Integrada.

Além dos sete profissionais listados no item anterior, a pesquisa contou a participação de mais oito profissionais, para coletar as impressões de especialistas, conforme indicado acima. Por parte da contratante foram também entrevistados o responsável pelo serviço de meio ambiente e desapropriações, o analista de meio ambiente, dois fiscais de obra e um responsável por licitações. Por parte de contratadas, a pesquisa foi acrescida por um engenheiro ambiental, um engenheiro de supervisão e um projetista.

\section{Resultados e discussão}

\section{Estudo de caso do processo de projeto em empreendimento público de grande porte}

\section{Estudos preliminares e definições de contrato}

Principal documento técnico dos estudos preliminares, o anteprojeto de engenharia foi dividido em duas partes. A primeira foi descritiva, contemplando a definição do objeto, parâmetros de orçamento, detalhes sobre o julgamento das propostas, tipos de garantias, obrigações das partes, forma de remuneração e termo de referência. Este contemplou de forma detalhada os parâmetros e normativas pertinentes para cada disciplina envolvida no empreendimento, priorizando requisitos baseados nodesempenho.

A segunda parte do anteprojeto apresentou a solução projetual em um estágio mais desenvolvido que o usual, ou seja, com um nível de soluções maior que o normalmente apresentado em anteprojetos. O anteprojeto já trazia diversas soluções, detalhes construtivos e definições relativas ao ciclo de vida do empreendimento. Um exemplo é a utilização de pavimento rígido em detrimento do pavimento flexível escolhido a partir de um estudo que levou em consideração a manutenção e a conservação do pavimento por um período de 20 anos.

Para a condução do empreendimento, além das especificações do anteprojeto de engenharia, termo de referência e edital, contratante e contratado ainda deveriam seguir as determinações da matriz de riscos. Esse 
documento contava com diversos eventos de riscos e foi resultado de um processo de análise multidisciplinar, que contou com as análises qualitativa e quantitativa de riscos, incluindo a simulação de Monte Carlo.

De maneira geral, a matriz de risco determinava que a empresa contratada deveria assumir todos os riscos relativos a acréscimos de quantitativos, de modificações de soluções, fundações e interferências, mesmo que os eventos não estivessem claramente listados na matriz de risco. A contratada ainda era obrigada a apresentar um seguro de risco de engenharia, com cobertura para situações como aumento de custos, problemas de qualidade eperda de produtividade.

Por outro lado, os riscos assumidos pela contratante ficavam atrelados a situações que gerassem alteração do escopo, tais como condicionantes ambientais, aumento de desapropriações, descobertas arqueológicas e outros eventos que não fossem decorrentes de erros ou omissões por parte do contratado.

No que diz respeito àremuneração, o processo era simplificado: consistia na aplicação do valor global apresentado na licitação a percentuais predefinidos no edital para grupos de serviços, tais como projeto, terraplenagem, drenagem eobras de artes especiais. Como previsto nalegislação, o contrato era claro no sentido de que não haveria revisão de valores contratados, exceto para a recomposição do equilíbrio econômico-financeiro em casos fortuitos ou necessidade de alteração do projeto a pedido da contratante.

Dessa maneira, a contratada ficou responsável pelo projeto, soluções, orçamento e obra, podendo adotar processos e técnicas a sua escolha no desenvolvimento dos projetos, desde que mantidos os requisitos mínimos do anteprojeto. Já o envolvimento do contratante se dava pela verificação do atendimento aos requisitos mínimos de desempenho e qualidade, remunerando a contratada de acordo com o andamento dos serviços em parcelas predefinidas no momento da contratação.

\section{Condução dos projetos}

O processo de projeto foi iniciado com a revisão do estudo de traçado, definindo, assim, os dados de entrada para o projeto. A partir de então foram criadas três frentes de trabalho distintas:

(a) pista dupla;

(b) binário novo; e

(c) binário existente.

Em momentos posteriores, as frentes de trabalho foram subdivididas em mais partes, que, segundo os entrevistados, eram necessárias para atender às demandas de trechos liberados em campo. A partir de informações prestadas foi possível elaborar o fluxo de análise de projeto, conforme apresentado na Figura 3.

Dessa maneira, o fluxo do processo de projeto para a Contratação Integrada, em estudo, baseou-se na compatibilização de três disciplinas mandatórias,geometria, terraplenagem e drenagem, considerando ainda a interface com as demais frentes de trabalho e contratos de túneis adjacentes.

Porém, não existia uma estrutura formal para fomentar a integração. O fluxo apresentado na Figura 3 foi identificado a partir das entrevistas com agentes envolvidos no projeto, consistindo, assim, no resultado de lições aprendidas durante a adaptação do fluxo normatizado para contratação tradicional, exemplificado na Figura 4.

Figura 3 - Fluxo da integração entre projeto e obra no lote estudado

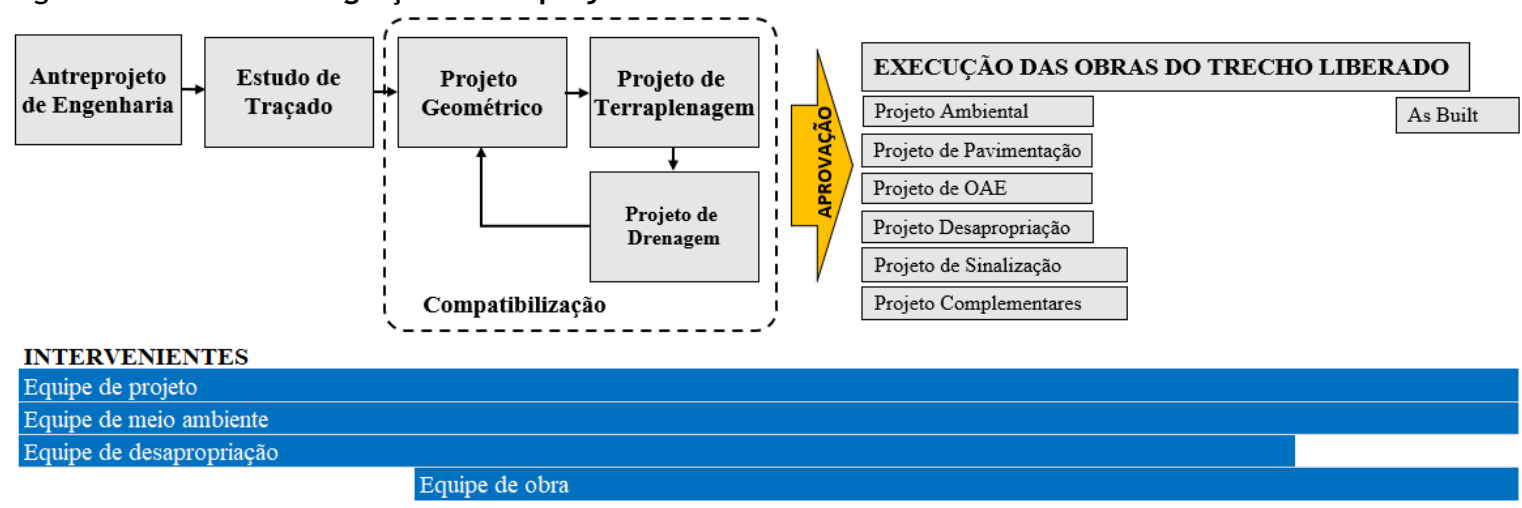


Figura 4 - Fluxo da elaboração de um projeto pelo método tradicional

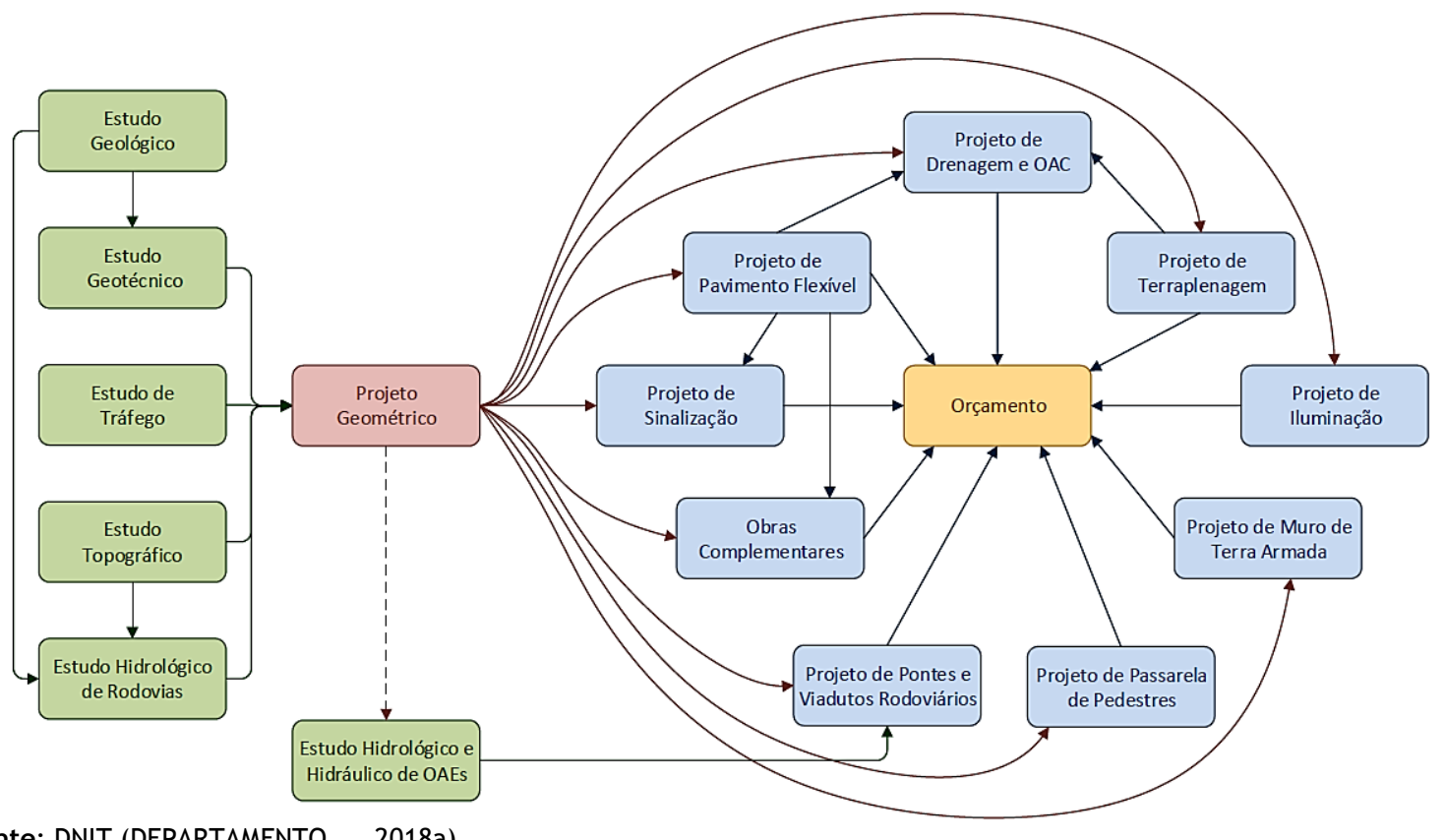

Fonte: DNIT (DEPARTAMENTO..., 2018a).

É possível observar que no fluxo para elaboração de um projeto tradicional existe um sequenciamento de atividades que direcionam o orçamento do empreendimento que nem sequer é considerado no fluxo da Contratação Integrada, tendo em vista que as questões de orçamento são fixadas no momento da licitação.

Devido às alterações substanciais no fluxo do processo da Contratação Integrada em relação ao método tradicional, alguns entrevistados pontuaram a necessidade de estudos mais detalhados para a definição de um fluxo definitivo, sugerindo, por exemplo, que o projeto de pavimentação também fosse integrado na compatibilização com os projetos de geometria, terraplenagem e drenagem.

Após a aprovação das disciplinas mandatórias, foi autorizado o início das obras do trecho liberado, bem como iniciada a elaboração dos projetos complementares, de forma a possibilitar o desenvolvimento simultâneo de projetos. Iniciaram-se as obras antes do término dos projetos, a partir das definições já existentes, o que é comum em projetos rodoviários que se apropriam dos conceitos de $\mathrm{DB}$, de acordo com Sullivan et al. (2017) e Park e Kwak (2017).

Com relação aos intervenientes no processo de projeto, foi verificada a participação da equipe de meio ambiente e desapropriação, desde a elaboração do anteprojeto, e da equipe de obra, a partir da compatibilização das disciplinas mandatórias de projeto. Contudo, essa atuação aconteceu de maneira não formalizada em processos, e não havia nenhuma exigência contratual nesse sentido.

Dessa maneira, apesar de ser constatada a existência de equipes multidisciplinares, não houve um procedimento sistemático ou formal para fomentar a integração com o uso de estruturas para comunicação conforme preconizado nas melhores práticas em DB ou no desenvolvimento integrado de projetos.

No que diz respeito à matriz de riscos, foram relatadas situações em que a contratante assumiu serviços necessários ao empreendimento, mas não previstos incialmente, como as soluções de interferências e acréscimo de volumes relativos à estabilização de taludes.

Verificou-se que o mecanismo de contratação não propiciava nenhum incentivo àredução de prazos de execução ou implementação de medidas para a melhoria da construtibilidade. Não foram previstos e implementados processos específicos de integração entre a equipe de projeto e a de obra - a colaboração aconteceu de maneira informal, por iniciativa dos coordenadores das equipes.

No campo de aplicações tecnológicas, foram verificados avanços iniciais no sentido de modelagem de projetos para produção, tentativa de implantação de um sistema em nuvem para compartilhar arquivos de projeto e uso de motoniveladora com lâmina automatizada mediante uso de equipamento e projeto georreferenciado. 
Com relação a adaptações e soluções de problemas em projeto a partir de solicitações da equipe de obras, foram levantados alguns tópicos, sinteticamente apresentados a seguir:

(a) alteração de superestrutura de ponte, prevista em vigas pré-moldadas de concreto, e alterada para vigas metálicas, no intuito de reduzir o tempo total de execução de obra em função da eliminação de pilares, mesmo considerando o custo mais elevado do material empregado;

(b) modificações do método construtivo de pingadeiras, que originalmente seriam moldadas in loco, para elementos pré-moldados, objetivando a industrialização de parte do processo produtivo, a eliminação de formas e a melhoria na manutenção e na durabilidade;

(c) alteração de parte do traçado no intuito de evitar interferência com linha férrea, o que resultou em maior volume de serviços, em detrimento do menor envolvimento com terceiros; e

(d) criação de norma específica para utilização de equipamento nuclear denominado gamadensímetro, para controle de compactação de aterros em substituição aos métodos do Frasco de Areia e do Speedy.

Segundo a maioria dos entrevistados, as alterações apresentadas relativas a adaptações em campo tiveram seus processos de aprovação facilitados em função da Contratação Integrada. Isso se deu em função da possibilidade de alterar aspectos conceituais de projeto de maneira distinta da prática convencional.

Além disso, a proximidade entre as equipes de projeto e de obra permitiu que parâmetros de melhoria de construtibilidade fossem adotados. As demais vantagens e aplicabilidade do método de contratação são abordadas na seção a seguir.

\section{Percepção dos especialistas sobre vantagens e desvantagens de projetos integrados em comparação com projetos tradicionais}

Os especialistas entrevistados manifestaram sua percepção sobre custo, prazo e qualidade da Contratação Integrada em comparação com os métodos tradicionais de licitação. Também foram questionados sobre quais tipos de obras rodoviárias seriam mais adequadas à aplicação do modelo de Contratação Integrada.

Com relação a custos, 9 dos 13 entrevistados consideraram que a Contratação Integrada pode diminuí-los, e somente 1 pontuou que o método poderia gerar aumento de custos. Os entrevistados apontaram dois fatores como incentivadores dessa redução: a impossibilidade de aditivos contratuais do objeto contratado e as responsabilidades assumidas pela contratada em virtude da matriz de riscos.

Dessa maneira, os especialistas sugeriram que, ainda que o custo final para a contratante possa ser menor, isso pode acontecer em função de a contratada assumir parte desses custos, diminuindo sua margem operacional.

Por outro lado, a possibilidade de aumento de custos foi ponderada em relação à precificação do risco que é acrescido ao valor máximo aceito pelo contratante, ao baixo desconto obtido no momento da contratação e aos valores necessários para a aquisição do seguro de risco de engenharia.

Com relação a prazos de execução, 11 dos 13 entrevistados que responderam à questão consideraram que o método alternativo pode diminuir os prazos. Ainda no quesito de prazos dos empreendimentos, nenhum dos entrevistados considerou seu aumento com o uso da Contratação Integrada.

As justificativas para a redução de prazos ficaram no campo da possibilidade de executar parte dos projetos em paralelo com as obras e a flexibilização de frentes de serviços e de decisões, o que pode abrir oportunidade para a utilização de novas tecnologias, bem como a diminuição de prazo relativo à eliminação de etapas licitatórias.

No que diz respeito aos aspectos de qualidade, tratados no questionário como atendimento ao escopo e às metas de desempenho, 7 dos 13 entrevistados que responderam à questão foram da opinião de que a Contratação Integrada proporciona melhoria da qualidade do projeto. Os demais acharam que não há diferença entre os modelos (5 entrevistados) ou 1 considerou que a Contratação Integrada diminui a qualidade do projeto.

Nesse aspecto, as opiniões pelo aumento da qualidade basearam-se no fato de que no modelo integrado a contratante tem a oportunidade de focar seus esforços em melhorar a qualidade das soluções, pois não precisa se debruçar nas questões de quantitativos e no valor unitário de cada serviço. No entanto, esse atendimento está atrelado à qualidade do anteprojeto de engenharia, ou seja, somente com um bom estudo preliminar é possível garantir a qualidade do empreendimento. 
Outro fator levantado foi que, em virtude de as soluções de projeto serem de responsabilidade da contratada, existe a tendência de serem melhores em função da responsabilidade envolvida na garantia dos serviços executados, não sendo possível imputar erros ao projeto durante a execução das obras.

Para os três campos de estudo (prazo, custo e qualidade) também foi destacado que se faz necessário dar maior atenção à etapa de projeto, de forma a permitir o desenvolvimento de melhores soluções técnicas.

Por fim, foram questionados, a partir de uma lista preestabelecida, quais os tipos de obras rodoviárias seriam indicados para utilização da Contratação Integrada, independentemente de questões de ordem legal ou regimental. Os 13 entrevistados responderam da seguinte maneira:

(a) obras de artes especiais (13 votos);

(b) construção/implantação/duplicação (11 votos);

(c) obras de adequação rodoviária (10 votos);

(d) manutenção com restauração (4 votos);

(e) manutenção simples (3 votos); e

(f) sinalização (3 votos).

Dessa maneira, os entrevistados consideraram que o modelo integrado não seria aplicável a todos os tipos de obras rodoviárias, com a tendência de destacar a aplicabilidade em empreendimentos de maior complexidade, comoobras de artes especiais, construção, implantação e duplicação rodoviária. Esse aspecto está em sintonia com constatações da literatura recente, parte delas apontadas no referencial teórico.

Para os aspectos inerentes a prazos, custos e qualidade, a pesquisa aponta para uma concordância com a avaliação sobre as práticas de DB (SULLIVAN et al., 2017), tendo em vista a melhor percepção sobre as vantagens de prazo em relação a custos e a indefinição a respeito da qualidade.

\section{Similaridade entre a Contratação Integrada e o Design-build}

Conforme verificado no estudo de caso, a Contratação Integrada, assim como o DB, contou com uma única fonte de responsabilidade pelo projeto e obra, abrindo a oportunidade para o envolvimento do construtor mais cedo no ciclo de vida do empreendimento. Tal fato possibilitou o início da construção antes da conclusão total dos projetos, facilitando, assim, adaptações e soluções de problemas durante o empreendimento.

Com relação às principais caraterísticas contratuais definidas em Yu, Shen e Shi (2017) e apresentadas no Quadro 1, a remuneração de um único ente responsável pelo projeto e obra na Contratação Integrada é compatível com o modelo internacional. Essa característica, se bem conduzida e gerenciada, pode proporcionar um alto nível colaboração entre as equipes de obras e projetos, como preconizado nas melhores práticas em DB.

No que diz respeito à gestão de riscos, foi verificada no estudo de caso a transferência da responsabilidade sobre a maioria dos eventos incertos para a contratada, bem como a efetiva materialização de parte desses eventos, restando à contratante a responsabilidade de assumir os ônus relativos a mudanças de escopo. Dessa maneira, na Contratação Integrada em estudo houve alto grau de risco para o contratado em detrimento do baixo risco para o contratante.

A grande transferência de riscos, aliada à responsabilidade técnica pelo projeto e à rigidez do orçamento, implicou à contratada maior envolvimento e responsabilidade no processo de projeto em comparação com a parte contratante, que apenas verificava a adequação técnica das soluções em relação ao anteprojeto de engenharia.

Como em grande parte dos empreendimentos há um nível de detalhamento baixo nos anteprojetos, o risco para as empresas contratantes tende a ser maior quando comparado ao do contratante. Tal fato sugere maior investimento em gestão por parte da contratada, tendo em vista a responsabilidade em garantir a qualidade das soluções de projeto, para então estudar possíveis reduções de custos e prazos do empreendimento.

A partir de tais constatações é possível elaborar um quadro contemplando as características do DB apuradas por Yu, Shen e Shi (2017) em comparação com o estudo de caso da Contratação Integrada, conforme apresentado no Quadro 3. 
Quadro 3 - Comparação entre os métodos de entrega DB e Contratação Integrada

\begin{tabular}{|l|c|c|}
\hline \multicolumn{1}{|c|}{ Critério de análise } & DB & $\begin{array}{c}\text { Contratação } \\
\text { Integrada }\end{array}$ \\
\hline Modo de pagamento & $\begin{array}{c}\text { O contratante paga o } \\
\text { único contratado }\end{array}$ & $\begin{array}{c}\text { O contratante paga o } \\
\text { único contratado }\end{array}$ \\
\hline Grau de colaboração entre o projetista e o empreiteiro & Alto & Possível \\
\hline Riscos para o contratado & Altos & Altos \\
\hline Riscos para o contratante & Baixos & Baixos \\
\hline Responsabilidade e envolvimento do contratado & Alta & Alta \\
\hline Responsabilidade e envolvimento do contratante & Baixa & Baixa \\
\hline Custos de gestão para o contratado & Altos & Altos \\
\hline Custos de gestão para o contratante & Baixos & Baixos \\
\hline Custos do projeto e construção para o contratado & Incertos & Incertos \\
\hline
\end{tabular}

Fonte: baseado emYu, Shen e Shi (2017).

A partir da constatação da similaridade entre os modelos é possível correlacionar com segurança a aplicabilidade das melhores práticas em DB, que passa pelo desenvolvimento integrado de projetos.

\section{Possibilidade de aplicação dos princípios de desenvolvimento integrado de projetos}

Partindo das ações para Engenharia Simultânea definidas por Fabrício (2002) e Bouchlaghem et al. (2006), e considerando os conceitos de Integrated Project Delivery de AIA (AMERICAN..., 2007) e Kuns e Fischer (2020), foi possível elaborar o Quadro 4, detalhado a seguir.

Um dos aspectos basilares da Engenharia Simultânea e de sua evolução no Integrated Project Delivery é a contratação e desenvolvimento antecipado das disciplinas de projeto, que passam a ser consideradas na etapa inicial,do estudo preliminar e da concepção das soluções. Essa ênfase no momento de concepção do produto pode ser facilitada pela Contratação Integrada em função da presença da construtora no processo, porém não é condição primordial para que ocorra a valorização dessa etapa.

Um exemplo disso foi constatado no estudo de caso em relação à solução do pavimento rígido em detrimento do pavimento flexível, definida no momento do desenvolvimento do projeto em separado da obra. É importante trazer à tona que as definições de desempenho no momento do anteprojeto são de suma importância no sentido de evitar que a contratada tome soluções de baixo custo em detrimento de lacunas deixadas no momento do anteprojeto.

Ainda que soluções otimizadas possam ocorrer nos processos tradicionais de contratação, particularmente quando o anteprojeto tiver parâmetros de desempenho claramente explicitados, a realização em paralelo de várias atividades no desenvolvimento do produto e a formação de equipes de projeto multidisciplinares só podem ser plenamente aplicadas em projetos integrados. Isso tendo em vista a importância da participação da equipe de obras nas definições de construtibilidade e otimização dos processos de produção, tanto que a participação da equipe de obra e a divisão do projeto em trechos distintos foram consideradas importantes contribuições para soluções de problemas observados durante a execução do empreendimento, sendo possível somente na Contratação Integrada. Por outro lado, esse mecanismo de contratação, embora possibilite maior integração entre as equipes de projeto e de obra, não garante que isso aconteça como atividade intrínseca ao modelo de contratação.

A participação da equipe de obras nas decisões de projeto não é passível de ser implementada nos projetos públicos tradicionais tendo em vista o lapso temporal entre as definições de projeto e a contratação da construtora responsável pela execução das obras. Essa constatação se repete no DBBe está em sintonia com observações da literatura recente, como em Eastiman et al. (2014), Park e Kwak (2017) e Sullivan et al. (2017), que observamque somente em projetos integrados é possível envolver o construtor no ciclo de vida do projeto.

Aspecto similar verifica-se com relação à questão do uso de tecnologia da informação apoiada pelo uso do BIM, pois a metodologia implementada sem a participação da equipe de obras limitaria o modelo a níveis iniciais na integração de políticas, processos e tecnologia. 


\section{Quadro 4 - Aplicabilidade da Engenharia Simultânea e Integrated Project Delivery nas contratações} tradicionais e integradas

\begin{tabular}{|l|c|c|}
\hline \multicolumn{1}{|c|}{ Prática } & \multicolumn{2}{c|}{$\begin{array}{c}\text { Aplicabilidade no } \\
\text { desenvolvimento do projeto }\end{array}$} \\
\cline { 2 - 3 } & $\begin{array}{c}\text { Contratação } \\
\text { tradicional }\end{array}$ & $\begin{array}{c}\text { Contratação } \\
\text { Integrada }\end{array}$ \\
\hline $\begin{array}{l}\text { Ênfase no momento da concepção do produto e valorização do } \\
\text { projeto }\end{array}$ & Total & Total \\
\hline $\begin{array}{l}\text { Orientação para a satisfação dos clientes e usuários para o ciclo } \\
\text { de vida de produtos e serviços }\end{array}$ & Total & Total \\
\hline Adoção de processos estruturados para coordenação de projetos & Total & Total \\
\hline $\begin{array}{l}\text { Realização em paralelo de várias atividades de desenvolvimento } \\
\text { do produto }\end{array}$ & Parcial & Total \\
\hline $\begin{array}{l}\text { Formação de equipes de projeto multidisciplinares e } \\
\text { coordenadas }\end{array}$ & Parcial & Total \\
\hline Utilização de tecnologias da informação preconizadas pelo BIM & Parcial & \multicolumn{2}{c|}{ Total } \\
\hline $\begin{array}{l}\text { Contratos relacionais: empreendedor, construtor e projetistas } \\
\text { compartilham responsabilidades, riscos e resultados do } \\
\text { empreendimento }\end{array}$ & $\begin{array}{c}\text { Não aplicável devido a } \\
\text { limitações legais }\end{array}$ \\
\hline
\end{tabular}

Fonte: baseado em Fabrício (2002), Bouchlaghem et al. (2006), AIA (AMERICAN..., 2007) e Kuns e Fischer (2020).

Dessa maneira, a análise do caso aponta para o fato de que em empreendimentos públicos a Contratação Integrada é um método que melhor se adéqua à implementação dos conceitos da Engenharia Simultânea. Porém, como constatado por Park e Kwak (2017), o poder público ainda não desfruta plenamente dos benefícios da utilização do método alternativo de integração entre projeto e obra. A adoção plena de conceitos de Integrated Project Delivery fica limitada por razões legais, já que, de fato, não se observa, entre outros aspectos, a existência de contratos relacionais.

Em função dos resultados apresentados, é possível elaborar uma síntese sobre os principais aspectos encontrados no estudo de caso, ações necessárias para a alavancagem no processo de projeto, e resultados esperados conforme apresentado na Figura 5.

Tanto a análise do caso como a opinião dos especialistas sugerem que a Contratação Integrada é mais propícia à implementação de conceitos de desenvolvimento integrado de projetos, porém, como sugeridona Figura 5, a Contratação Integrada não garante, como aspecto intrínseco à estrutura contratual, maior integração entre os agentes, sendo necessárias exigências adicionais para a condução do processo de projeto.

O que se verificou no estudo de caso foram iniciativas próprias dos coordenadores de projeto, que podem estar atreladas à grande transferência de riscos na Contratação Integrada e à impossibilidade de aditivos, o que pode ter sido um indutor para o desenvolvimento de soluções otimizadas, tendo em vista a pressão para a redução de erros.

Dessa maneira, cabe destacar que, devido à transferência de riscos à empresa contratada em um ambiente de incerteza elevada, o modelo de Contratação Integrada não pode ser utilizado de maneira irrestrita. O modelo seria aplicável, independentemente de análise legal ou regimental, em projetos complexos que se beneficiem de soluções de projeto desenvolvidas em conjunto com a equipe de obras.

Em resumo, a Contratação Integrada pode ser considerada uma abordagem DB, podendo trazer vantagens na redução dos prazos contratuais em ambientes complexos desde que aplicados os conceitos de desenvolvimento integrado de projetos.

Nesse sentido, dadas as poucas pesquisas existentes nesse campo, o presente trabalho contribuino sentido de melhor caracterizar do ponto de vista técnico essa modalidade de contratação.Por se tratar de um único estudo de caso, os achados aqui apresentados poderão ser comparados aos resultados de outros estudos, possibilitando maior ou menor grau de generalização das contribuições apresentadas.

A partir da constatação das semelhanças com a estrutura conceitual do DB, diretrizes para aprimoramento dos processos de projeto e obra desenvolvidas para aquela modalidade de contratação poderão ser adaptadas para o caso brasileiro, como desdobramento das ações sugeridas na Figura 5, o que pode ser tema de trabalhos futuros no âmbito acadêmico. 
Figura 5 - Integração entre projeto e obra em empreendimentos complexos

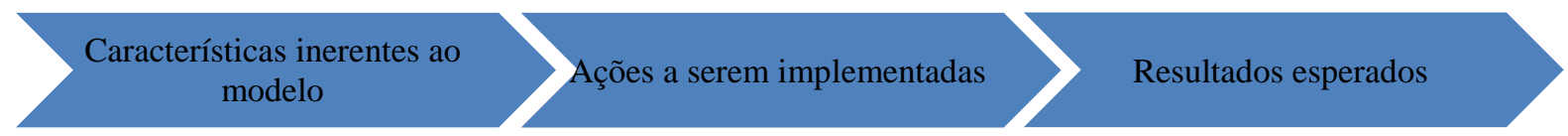

- Intervenção da equipe de obras no desenvolvimento do projeto.

- Execução de projetos por etapas de obras.

- Execução de projetos auxiliares concomitantemente à obras.

- Processos facilitados para aprovação nas alterações de projeto.

- Análise de riscos.
- Envolver antecipadamente a equipe de obra,fornecedores e consultores.

- Exigir contratualmente a integração de equipes multidisciplinares.

- Definir claramente metas de desempenho do projeto levando em consideração todo o ciclo de vida do empreendimento.

- Fazer gestão de riscos.

- Desenvolver uma estrutura com fluxos formais de processos.

- Utilizar tecnologias da informação e comunicação (BIM).

- Criar sistema de incentivo com foco na redução de custos e/ou prazos.
- Melhoria nas questões de construtibilidade.

- Soluções inovadoras e transferências denovas tecnologias.

- Redução do prazo do empreendimento.

- Manutenção ou redução de custos.

- Menor índice de abandono de obras.

Por fim, cabe salientar as limitações inerentes ao método do estudo de caso, ainda mais considerando tratarse de caso único, embora relevante. Não obstante, os resultados comentados permitem a identificação dos principais aspectos associados ao modelo alternativo de contratação que faz parte de estudos para a revisão da lei geral de licitações no Brasil.

\section{Conclusão}

O presente estudo permitiu uma análise sobre os mecanismos de integração entre as fases de projeto e obra em um empreendimento público de grande porte considerando o modelo de Contratação Integrada.

Foi realizada uma comparação com a prática atual de referência internacional conhecida como Design-build. Nesse sentido, o trabalho apresentou uma análise ainda inédita, aprofundando aspectos técnicos de um marco legal ainda pouco explorado no âmbito acadêmico brasileiro.

Tendo em vista os poucos estudos nacionais sobre o tema, que é de caráter complexo e contemporâneo, o método do estudo de caso foi adequado para a condução do trabalho e cumpriu com o objetivo de compreender o processo de contratação, sua aplicabilidade, vantagens e desvantagens.

No caso em questão, a Contratação Integrada pôde ser considerada uma abordagem Design-build dentro das variações internacionais do modelo, pois mantém a característica primordial de contratação de um único ente responsável pelo projeto e obra, podendo envolver o construtor mais cedo no ciclo de vida do empreendimento.

Dessa maneira, o estudo de caso sugere que a Contratação Integrada possa serum modo de contratação que abre oportunidade para a aplicação de maneira profunda dos conceitos de desenvolvimento integrado de projetos, em ambiente de Engenharia Simultânea, possibilitando também alcançar os níveis mais avançados da metodologia Building Information Modelling (BIM) em empreendimentos públicos de caráter complexo.

Contudo, a Contratação Integrada induz, mas não garante, as vantagens inerentes à integração entre projeto e obra. Essa estrutura contratual não é por si só suficiente para a implantação das práticas inovadoras na gestão do processo de projetos integrados.

Com base no referencial teórico, cabe afirmar que é necessária a implementação de um conjunto de ações que passam por desenvolver um anteprojeto de qualidade, bem como fluxos de processos de projetos 
específicos, exigências contratuais que induzam a integração multidisciplinar e utilização de tecnologia da informação.

Por fim, cabe salientar que a aplicabilidade da Contratação Integrada, assim com o Design-build, deve estar atrelada (além dos fatores legais e normativos) a uma análise de vantagens em relação à grande transferência de riscos envolvida no modelo, o que pode gerar menos descontos na fase contratual ou ainda abandono de obras por inviabilidade econômica.

\section{Referências}

AMERICAN INSTITUTE OF ARCHITECTS. Integrated project delivery: a guide. 2007. Disponível em: https://www.aiacontracts.org/. Acesso em: 08 fev. 2020.

BOUCHLAGHEM, D. et al. ICT - Enabled Collaborative Working Environment for Concurrent Conceptual Design. Architectural Engineering and Design Management, v. 1, p. 261-280, 2006.

BRADLEY, A. et al. BIM for Infrastructure: an overall review and constructor perspective. Automation in Construction, v. 71, p. 139-152, 2016.

BRASIL. Lei n ${ }^{\circ} 12.462$, de 4 de agosto de 2011, que institui o Regime Diferenciado de Contratações Públicas - RDC e dá outras providências. Diário Oficial da União, Brasília, 10 ago. 2011.

BRASIL. Lei n 8.666, de 21 de junho de 1993, que regulamenta o art. 37, inciso XXI, da Constituição Federal, institui normas para licitações e contratos da Administração Pública e dá outras providências. Diário Oficial da União, Brasília, 6 jul. 1994.

CHO, K. et al. Partnering process model for public-sector fast-track design-build projects in Korea. Journal of Management in Engineering, v. 26, n. 1, p. 19-29, 2010.

DEPARTAMENTO NACIONAL DE INFRAESTRUTURA DE TRANSPORTES. Cartilha institucional das obras de duplicação, modernização e implantação da BR-381/MG Norte. Belo Horizonte: DNIT, 2018a.

DEPARTAMENTO NACIONAL DE INFRAESTRUTURA DE TRANSPORTES. Guia de análise de projetos rodoviários. 2018b. Disponível em: http://www.dnit.gov.br/planejamento-epesquisa/desenvolvimento-e-projetos-1/1_GuiadeAnalise_Leituradigital_V3_.pdf. Acesso em: 18 fev. 2019.

DESIGN-BUILD INSTITUTE OF AMERICA. Design-build done right: best design-build practices. v. 2 , 2014. Disponível em: https://dbia.org/wp-content/uploads/2018/04/Best-Practices-UniversallyApplicable.pdf. Acesso em: 19 nov. 2018.

EASTIMAN, C. et al.Manual de BIM: um guia de modelagem da informação da construção para arquitetos, engenheiros, gerentes, construtores e incorporadores. Porto Alegre: Brookman, 2014.

FABRICIO, M. M. Projeto Simultâneo na construção de edifícios.São Paulo, 2002. Tese (Doutorado em Engenharia de Construção Civil e Urbana) - Escola Politécnica, Universidade de São Paulo, São Paulo, 2002.

FEDERAL HIGHWAY ADMINISTRATION. Design-Build Effectiveness Study. 2006. Disponível em: https://www.fhwa.dot.gov/reports/designbuild/designbuild.pdf. Acesso em: 20 out. 2018.

FREIRE, F.; ANDERY, P.; BOMTEMPO, S. Um estudo exploratório sobre o processo de projeto de obras públicas usando o RDC - Regime Diferenciado de Contratação. In: ENCONTRO NACIONAL DE TECNOLOGIA DO AMBIENTE CONSTRUÍDO, 16., São Paulo, 2016. Anais [...] Porto Alegre: ANTAC, 2016.

GATTI, U. C.; MIGLIACCIO, G. C.; LAIRD L. Design management in design-build megaprojects: SR 99 Bored Tunnel Case Study. Practice Periodical on Structural Design and Construction, v. 19, n. 1, p. 148$158,2014$.

GIL, A. C. Métodos e técnicas de pesquisa social. 6. ed. São Paulo: Atlas, 2008.

KIM, Y. et al. Integrated project delivery in public projects: limitations and opportunity. In: ANNUAL CONFERENCE OF THE INTERNATIONAL GROUP FOR LEAN CONSTRUCTION, 24., Boston, 2016. Proceedings [...] Boston, 2016.

KUNZ, J.; FISCHER M. Virtual design and construction. Construction Management and Economics, v. 38 , n. 4 , p. $355-363,2020$. 
LING, F. Y. Y.; POH, B. H. M. Problems encountered by owners of design-build projects in Singapore. International Journal of Project Management, v. 26, p. 164-173, 2008.

MCKINSEY GLOBAL INSTITUTE.Reinventing construction through a productivity revolution. 2017. Disponível em: https://www.mckinsey.com/industries/capital-projects-and-infrastructure/ourinsights/reinventing-construction-through-a-productivity-revolution. Acesso em: 4 fev. 2019.

MINCHIN JUNIOR, R. E. et al.Comparison of cost and time performance of design-build and design-bidbuild delivery systems in Florida. Journal of Construction Engineering and Management, v. 139, n. 10, p. 04013007-3, 2013.

NÓBREGA, M. O processo de mudança dos mecanismos das compras governamentais no Brasil: vantagens e riscos da contratação integrada. Revista do Tribunal de Contas do Estado de Minas Gerais (TCEMG), Belo Horizonte, v. 33, p. 23-37, abr./jun. 2015.

PARK, J.; KWAK, Y. H. Design-Bid-Build (DBB) vs. Design-Build (DB) in the U.S. public transportation projects: the choice and consequences. International Journal of Project Management, v. 35, n. 3, p. 280295, 2017.

SERRADO, I. P. et al. Identification of importance levels of market risks in the construction sector. Journal of Engineering, Project \&Production Management, v. 9, n. 2, p. 74-84, 2019.

SINDICATO DA ARQUITETURA E DA ENGENHARIA. RDC/Contratação Integrada, Análise de Contratações de Transporte Rodoviário. 2019. Disponível em: http://sinaenco.com.br/wpcontent/uploads/2019/06/RDC-Contrata\%C3\%A7\%C3\%A3o-Integrada-An\%C3\%A1lise-deContrata\%C3\%A7\%C3\%B5es.pdf. Acesso em: 29 ago. 2019.

SULLIVAN, J. et al. Two decades of performance comparisons for design-build, construction manager at risk, and design-bid-build: quantitative analysis of the state of knowledge on project cost, schedule, and quality. Journal of Construction Engineering and Management, v. 143, n. 6, p. 04017009-1-0401700911, 2017.

TRAN, D. Q.; DIRAVIAM, G.; MINCHIN JUNIOR, R. E. Performance of highway design-bid-build and design-build projects by work types. Journal of Construction Engineering and Management, v. 144, n. 2, p. 04017112-1-04017112-9, 2018.

TRAN, D. Q.; MOLENAAR, K. R. Impact of risk on design-build selection for highway design and construction projects. Journal of Management in Engineering, v. 30, n. 2, p. 153-162, 2014.

TRIBUNAL DE CONTAS DA UNIÃO. Acórdão no 306/2017. Plenário. Relator: Ministro Bruno Dantas. Sessão de 22/2/2017. Disponível em: https://portal.tcu.gov.br/inicio/index.htm. Acesso em: 20 out. 2018.

YU T.; SHEN G. Q.; SHI Q. Comparing the performance quality of design-bid-build and design-build delivery methods. Journal of Construction Engineering and Management, v. 143, n. 4, p. 04016111-104016111-10, 2017.

ZACARIAS, L. G. et al. Estudo de caso da aplicação do RDC em obra pública de infraestrutura. In: SIMPÓSIO BRASILEIRO DE GESTÃO E ECONOMIA DA CONSTRUÇÃO, 11., Londrina, 2019. Anais [...] Porto Alegre: ANTAC, 2019.

\section{Ronan Lana Alves Moreira}

Departamento de Engenharia de Materiais e Construção | Universidade Federal de Minas Gerais | Av. Pres. Antônio Carlos, 6627 | Belo Horizonte - MG - Brasil | CEP 31270-901 | Tel.: (31) 3409-1856 | E-mail: ronanlana1@gmail.com

\section{Paulo Roberto Pereira Andery}

Departamento de Engenharia de Materiais e Construção | Universidade Federal de Minas Gerais | E-mail: paulo@demc.ufmg.br

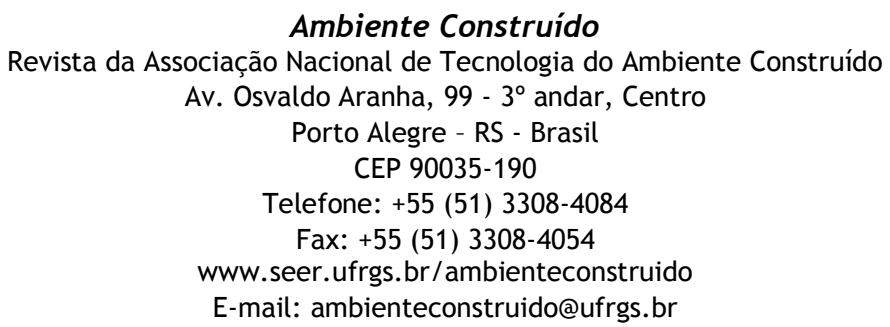

